\title{
Dynamics of African swine fever virus (ASFV) infection in domestic pigs infected with virulent, moderate virulent and attenuated genotype II ASFV European isolates.
}

\author{
Carmina Gallardo ${ }^{1}$, Alejandro Soler ${ }^{1}$, Imbi Nurmoja ${ }^{2}$, Cristina Cano-Gómez ${ }^{1}$, S. \\ Cvetkova $^{3}$, Maciej Frant ${ }^{4}$, Grzegorz Wozniakowski ${ }^{5}$, Alicia Simon ${ }^{1}$, Covadonga Perez ${ }^{1}$, \\ Nieto R. ${ }^{1}$, and Marisa Arias ${ }^{1}$ \\ ${ }^{1}$ European Union Reference Laboratory for African Swine Fever (EURL) Centro de \\ Investigación en Sanidad Animal CISA INIA-CSIC Valdeolmos 28130 Madrid Spain \\ ${ }^{2}$ Estonian NRL Estonian Veterinary and Food Laboratory Kreutzwaldi 30 Tartu 51006 \\ Estonia \\ ${ }^{3}$ Latvia NRL Laboratory of Microbiology and Pathology Institute of Food Safety Animal \\ Health and Enviroment BIOR" Riga LV-1050 Latvia \\ ${ }^{4}$ Poland NRL Veterinærinstituttet/National Veterinary Institute Al Partyzantow 57 24-100 \\ Pulawy Poland \\ ${ }^{5}$ Department of Diagnostics and Clinical Sciences Faculty of Biological and Veterinary \\ Sciences Nicolaus Copernicus University in Toruń Lwowska 1 87-100 Toruń Poland
}

June 18, 2021

\begin{abstract}
This study aimed to compare the infection dynamics of three genotype II African swine fever viruses (ASFV) circulating in Europe. Eighteen domestic pigs divided into three groups were infected intramuscularly or by direct contact with two haemadsorbent ASFVs (HAD) from Poland (Pol16/DP/OUT21) and Estonia (Est16/WB/Viru8), and with the Latvian nonHAD ASFV (Lv17/WB/Rie1). Parameters such as symptoms, pathogenicity, and distribution of the virus in tissues, humoral immune response, and dissemination of the virus by blood, oropharyngeal and rectal routes were investigated. The Polish ASFV caused a case of rapidly developing fatal acute disease, while the Estonian ASFV caused acute to subacute infections in the presence of surviving animals. In contrast, animals infected with the ASFV from Latvia developed a more subtle, mild, or even subclinical disease. Oral excretion was sporadic or even absent in the attenuated group, whereas in animals that developed an acute or subacute form of ASF, oral excretion began at the same time as in the blood, or even 3 days earlier, and persisted up to 22 days. Regardless of virulence, blood was the main route of transmission of ASFV and infectious virus was isolated from persistently infected animals for at least 19 days in the attenuated group and up to 44 days in the group of moderate virulence. Rectal excretion was limited to the acute phase of infection. In terms of diagnostics, the ASFV genome was detected in contact pigs from oropharyngeal samples earlier than in blood, independently of virulence and, together with blood, both samples could cover a longer range to detect ASFV infection. The results presented here provide quantitative data on the spread and excretion of ASFV strains of different virulence among domestic pigs that can help to better focus surveillance activities and thus increase the ability to detect ASF introductions earlier.
\end{abstract}

\section{Hosted file}

ID TBED-OA-318-21 REVIEWED\&amp;CLEAN.docx available at https://authorea.com/users/420374/ articles/526742-dynamics-of-african-swine-fever-virus-asfv-infection-in-domestic-pigs- 
infected-with-virulent-moderate-virulent-and-attenuated-genotype-ii-asfv-europeanisolates
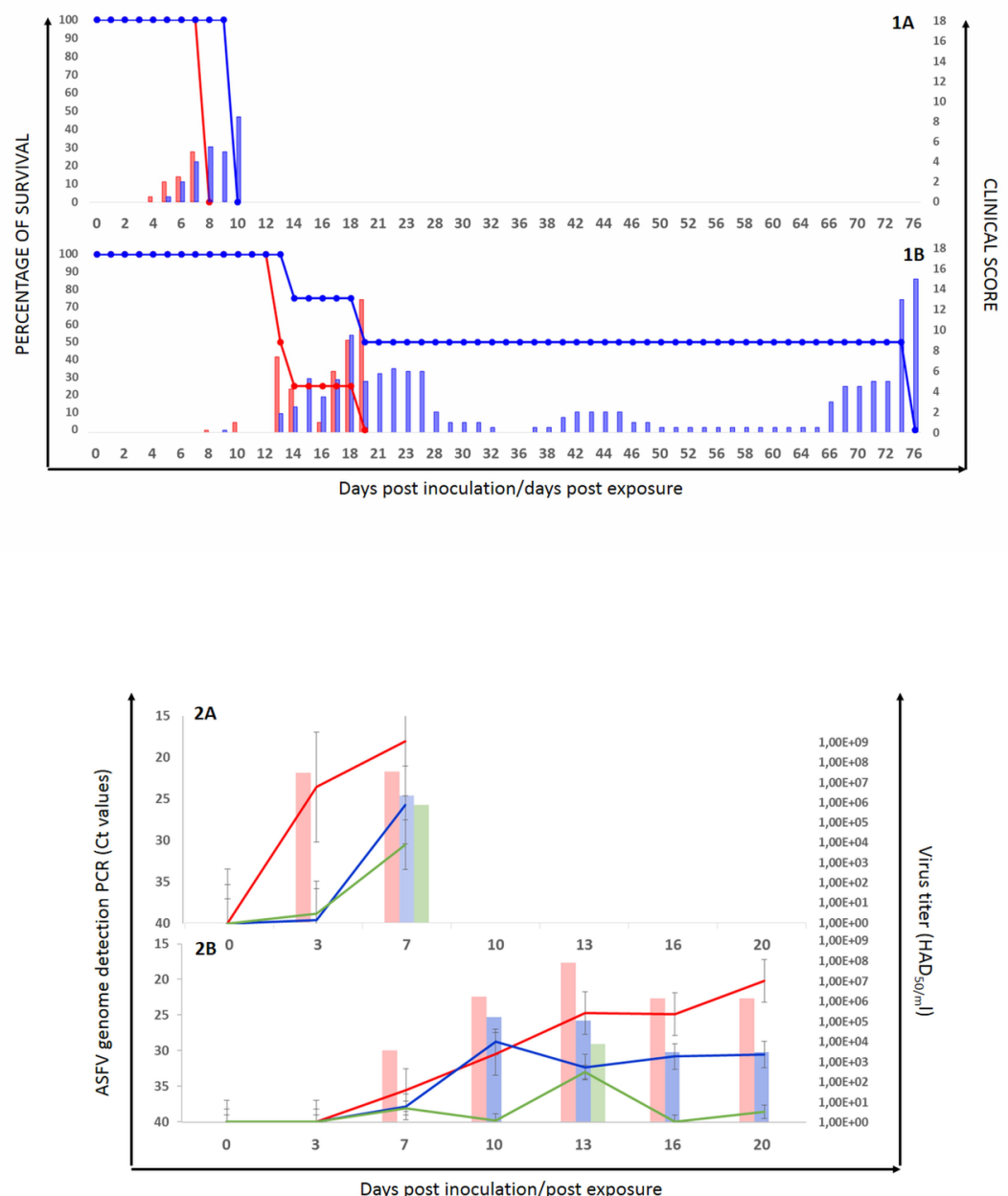

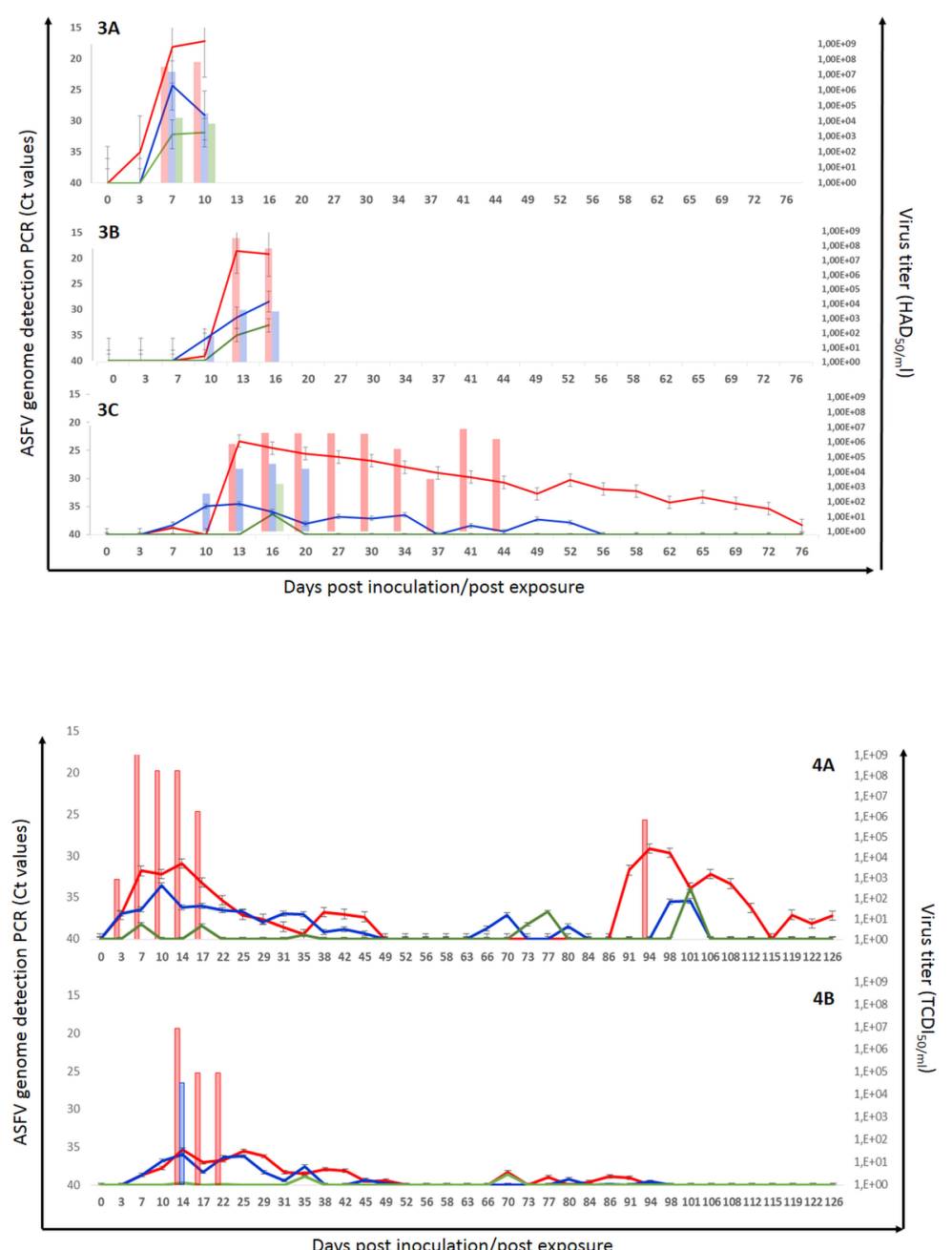

\section{Hosted file}

Tables.docx available at https://authorea.com/users/420374/articles/526742-dynamicsof-african-swine-fever-virus-asfv-infection-in-domestic-pigs-infected-with-virulentmoderate-virulent-and-attenuated-genotype-ii-asfv-european-isolates 